\title{
Corpus Callosum Involvement as Extrahepatic Manifestation of Hepatitis E Virus: An Uncommon Entity
}

\author{
Monika Singla ${ }^{1}$ Parth Bansal ${ }^{1}$ Venkatesh Sajja ${ }^{1} \quad$ Kapil Dev ${ }^{2}$ \\ ${ }^{1}$ Department of Neurology, Dayanand Medical College and \\ Hospital, Ludhiana, Punjab, India \\ 2Department of Medicine, Dayanand Medical College and Hospital, \\ Ludhiana, Punjab, India

\begin{abstract}
Address for correspondence Monika Singla, DM, 20-A, Rajguru Nagar, Near MBD Mall, Ludhiana 141012, Punjab, India (e-mail:drmonika78@yahoo.com).
\end{abstract}

J Neurosci Rural Pract 2021;12:427-430.
Abstract
Keywords
- hepatitis E virus
- neurological involvement
- extra-hepatic involvement
- corpus callosum hyperintensity

Hepatitis E virus (HEV) is a common cause of acute hepatitis worldwide. HEV infection is not limited only to liver but has various extrahepatic manifestations. Virus can affect various organs like pancreas, lymph nodes, hematological system, kidneys, spleen, central, and peripheral nervous system. We hereby present a case of 19-year-old patient with interesting finding on magnetic resonance imaging brain-related with hepatitis $E$.

\section{Introduction}

Worldwide hepatitis E virus (HEV) is an important public health problem. Every year there are approximately 20 million HEV-infected cases as per World Health Organization data usually having a self-limiting course, getting resolved within 1 to 2 months in case of acute infection, but sometimes leading to fatal infection if not treated well in time. As per literature, there may be approximately 50 to 60,000 hepatitis E-related deaths worldwide. ${ }^{1}$

Besides liver, extrahepatic manifestations of HEV are common. This effect may be due to HEV replication leading to direct viral effects or by various immune-mediated mechanisms indirectly affecting other organs. ${ }^{2}$ Out of various extrahepatic manifestations, only $5.5 \%$ patients of hepatitis E virus (HEV) disease have neurological complications, most common neurological manifestations found are Guillain-Barre syndrome, painful peripheral sensory neuropathy, neuralgic amyotrophy, brachial neuritis, proximal myopathy, cranial nerve palsies, Bell's palsy, seizures, meningo-encephalitis, encephalopathy, transverse myelitis, pseudo-tumor cerebri, and ataxia. ${ }^{3}$ Various brain magnetic resonance imaging changes reported are in basal ganglia, substantia nigra, and supratentorial and infratentorial and cortical hyperintensities; it may be associated with diffusion restriction or contrast enhancement occasionally. ${ }^{4-6}$ Our patient showed different area of involvement in brain which has not been reported yet in literature.

We hereby report an unusual case of a young man presenting to our emergency department with acute encephalopathy syndrome and corpus callosum hyperintensity associated with HEV infection.
DOI https://doi.org/

10.1055/s-0041-1723043

ISSN 0976-3147.
(C)2021. Association for Helping Neurosurgical Sick People.

This is an open access article published by Thieme under the terms of the Creative Commons Attribution-NonDerivative-NonCommercial-License, permitting copying and reproduction so long as the original work is given appropriate credit. Contents may not be used for commercial purposes, or adapted, remixed, transformed or built upon. (https://creativecommons.org/licenses/by-nc-nd/4.0/).

Thieme Medical and Scientific Publishers Pvt. Ltd. A-12, 2nd Floor, Sector 2, Noida-201301 UP, India 


\section{Case History}

A 19-year-old young man presented to our emergency department with history of fever for 5 days before admission, which was $103^{\circ} \mathrm{F}$ at the time of admission, with watery stools, 10 to 15 episodes in a day. Fever was associated with pulsatile, holocranial headache followed by low sensorium. On examination, patient was found in drowsy state, not following commands. Pupils were bilateral mid-dilated but reacting to light. There was no neck rigidity. He was moving his limbs spontaneously. Though patient was not cooperative for detailed power assessment, but in upper limbs, his power was found to grade $3 / 5$ and grade $2 / 5$ in lower limbs, with hypertonia and brisk reflexes. His knee and ankle reflexes were grade 3 . His plantar reflexes were extensor on examination.

In view of the history of fever with headache, with watery diarrhea, possibility of infective etiology was kept, likely to be acute gastroenteritis with encephalopathy/viral encephalitis/tropical fever with encephalopathy. Besides routine hematology and biochemical profile, cultures and viral markers with tropical fever workup were sent. His hemoglobin was $12.0 \mathrm{~g} / \mathrm{dL}$, platelet count came out to $56 \times 10^{9} / \mathrm{L}$ and total leukocyte count was $3.5 \times 10^{3} / \mathrm{L}$. His aspartate aminotransferase was 1,035 IU/L which reduced to $396.0 \mathrm{IU} / \mathrm{L}$ after 5 days, and alanine aminotransferase was $536.0 \mathrm{IU} / \mathrm{L}$ which

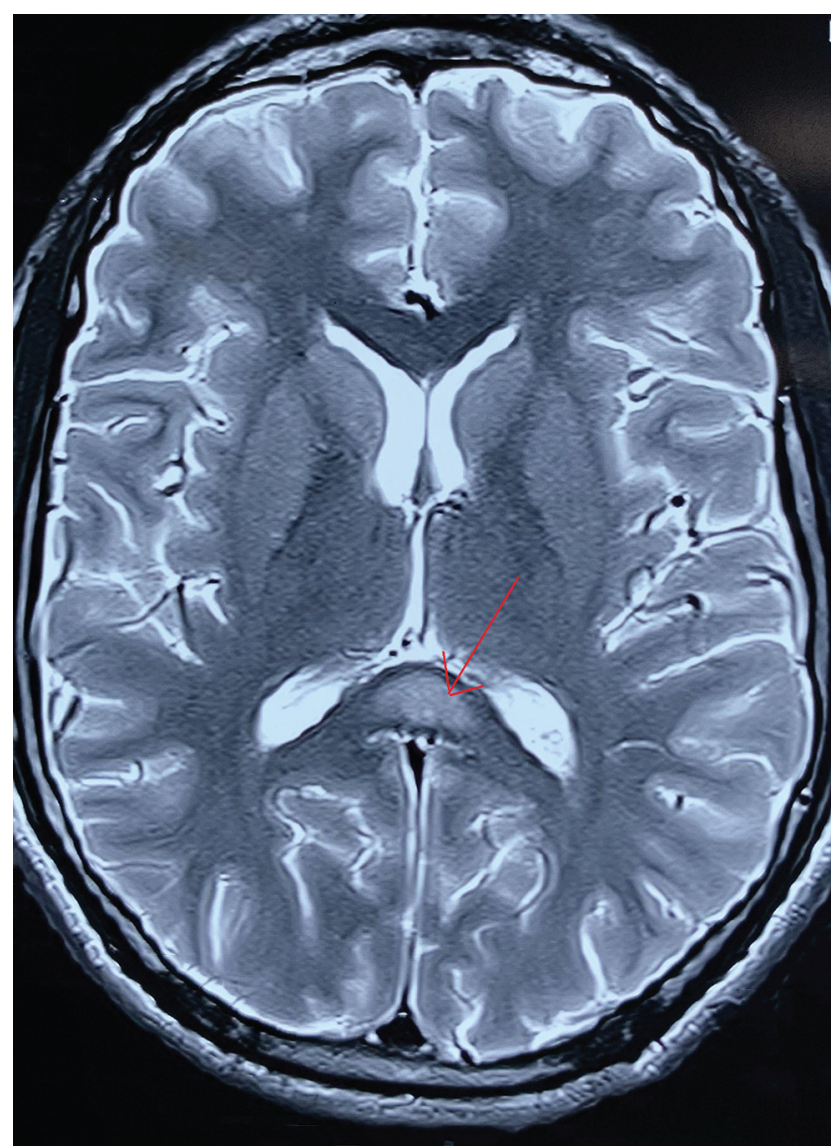

Fig. 1 T2 weight axial magnetic resonance image showing corpus callosum hyperintensity, (marked with red arrow) with no other white or gray matter lesions. reduced to $339 \mathrm{IU} / \mathrm{L}$. Coagulation profile was normal. Serum ammonia estimation was normal, $44 \mu \mathrm{mol} / \mathrm{L}$. Magnetic resonance imaging (MRI) brain with contrast was done which was showing corpus callosum hyperintensity ( - Fig. 1), with diffusion restriction, especially in splenium of corpus callosum (-Fig. 2). There was no contrast enhancement. Magnetic resonance venography was within normal limits. Once his platelet counts improved more than $75 \times 10^{9} / \mathrm{L}$, we performed his lumbar puncture. Cerebrospinal fluid total leucocyte count was $02 \times 10^{9}$ cells/L, with normal glucose and protein levels. His cerebrospinal fluid (CSF) examination for gram staining, fungal, tubercular, gene expert, and viral panel in cerebrospinal fluid was negative. Other fever work-up including dengue serology, leptospira serology, scrub typhus serology, plasmodium falciparum, and Plasmodium vivax antigen detection for malaria came out be negative, though his procalcitonin value came out be $2.17 \mathrm{ng} / \mathrm{mL}$ suggestive of sepsis. HEV IgM antibody came out to be 9.40 index value, which was significantly positive though other viral markers were negative. In view of transaminitis along with thrombocytopenia, possibility of tropical fever with encephalopathy was kept and was managed accordingly. Patient was started on ceftriaxone $2 \mathrm{gm} /$ day and ofloxacin $400 \mathrm{mg} /$ day, along with intravenous fluids in view of fever with diarrhea. Possibility of para-infectious changes and encephalitis was kept in view of MRI brain changes, though his CSF findings were normal

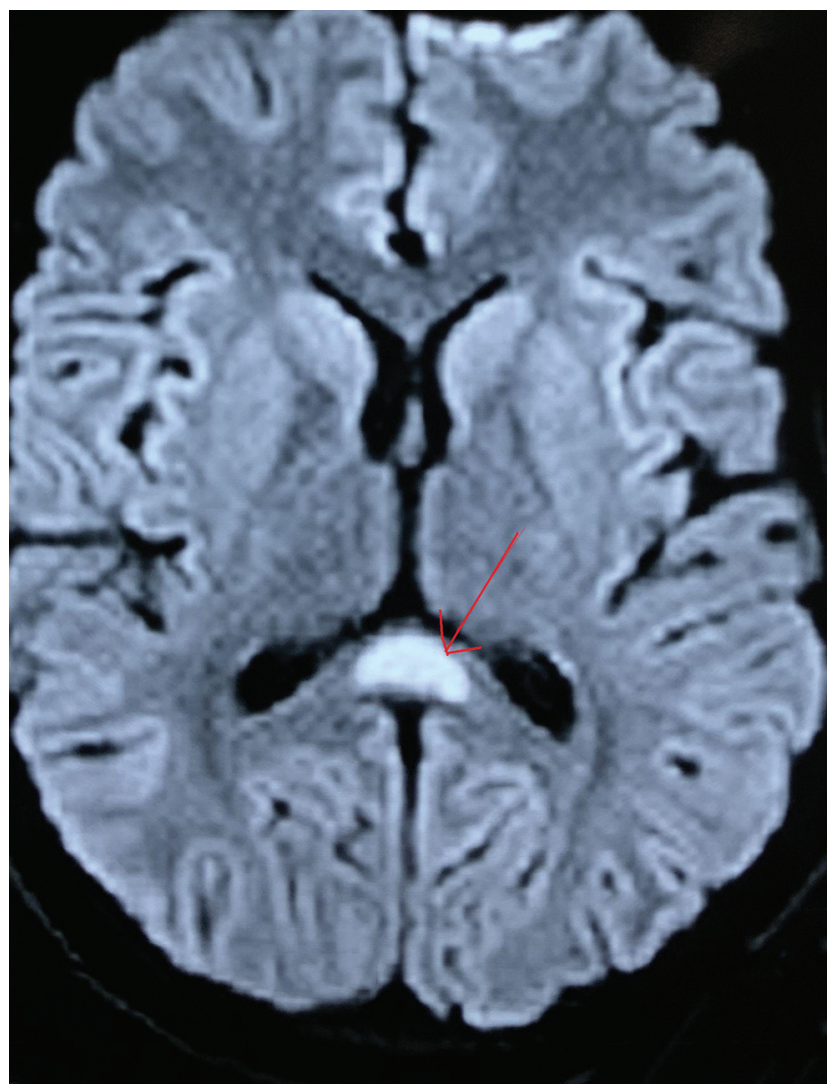

Fig. 2 Diffusion weighted axial image showing area of cytotoxic edema in corpus callosum (splenium) (marked with red arrow) suggestive of diffusion restriction in corpus callosum. 
and did not support the diagnosis. Intravenous steroids were started because of thrombocytopenia. Patient improved clinically with conservative management. On follow-up after 3 months of admission, MRI brain showed complete reversibility of corpus callosum hyperintensity. He had complete recovery of neurological deficit and able to walk independently. His platelet counts also improved to $190 \times 10^{9} / \mathrm{L}$.

\section{Discussion}

Our patient presented with fever and altered sensorium, found to have transaminitis, thrombocytopenia and was diagnosed to have HEV infection. HEV can present with neurological symptoms in two ways, in majority of cases as peripheral nervous system involvement and less commonly as central nervous system involvement in form of meningoencephalitis and transverse myelitis, rarely reported parkinsonism.,7 Neurological presentations of HEV are extremely rare and corpus callosum hyperintensities are not been reported so far. Our patient had no prior illness and was absolutely normal before this episode. In our patient, there was a temporal relationship between fever, the neurological involvement as evident by corpus callosum hyperintensity, with transaminitis and evidence of HEV infection. Other potential hepatotropic and neurotropic viral, and other causes were excluded suggesting this association as causal. Corpus callosum lesions are associated with infections, epilepsy, sudden withdrawal of antiepileptic drugs, metabolic abnormalities, brain infarction, drug therapy, cerebral trauma, malignancy, multiple sclerosis, subarachnoid hemorrhage, infections including tubercular meningitis, HIV, and other entities like hypoglycemia and hemolytic uremic syndrome..$^{89}$ Various gastrointestinal infections such as Salmonella, Escherichia coli, Epstein-Barr virus, or rotavirus may cause these lesions. ${ }^{10,11}$ Reversible lesions of corpus callosum are also reported with influenza, adenovirus, hepatitis A virus, and mumps. ${ }^{12} \mathrm{~A}$ series of the cases of transient diffusion restriction of corpus callosum are reported with influenza $A$ virus infection. ${ }^{13}$ Serum cytokine levels are markedly elevated in this condition. There is release of the inflammatory cytokines interleukin 1 (IL-1) and IL-6. Release of these cytokines begins the cascade that leads to cytokinopathy and leads to the diffuse callosal involvement. ${ }^{14}$ Various postulates have been proposed for corpus callosal involvement including intramyelin edema, migration of inflammatory cells, cytotoxic immunological reaction leading to microvascular endothelial injury, direct viral invasion, and osmotic demyelination. When there is corpus callosum lesion in the brain, clinically patient can present with altered sensorium, confusion, seizure, hemiparesis, headache, dysarthria, and increased muscle tone. Our patient also presented in confusion state, along with weakness and headache.

Another finding in our patient was thrombocytopenia, which is also associated with HEV infection and may be secondary to immunological reaction of virus. The mechanism of severe thrombocytopenia is believed to be immune mediated, and platelet-associated antibodies were found in few patients. Studies have shown response to intravenous immunoglobulin, plasma exchange, and/or corticosteroids in these particular patients, though some patients improve spontaneously. ${ }^{15}$

This corpus callosal hyperintensity has not been reported in HEV infection previously. In any patient presenting with fever, gastrointestinal symptoms, and transaminitis regardless of age, diagnosis of HEV infection may be considered, especially in endemic areas and if there is history of food or water contamination. Early suspicion and diagnosis can lead to better prognosis.

\section{Conclusion}

Though neurological manifestations are not very common with HEV, still we need to have strong suspicion to diagnose this particular entity. Corpus callosal hyperintensity not being reported earlier with this particular virus. It is a rare manifestation, as seen in our patient.

\section{Key Points}

- Neurologists and hepatologists should be aware of relation of acute or chronic HEV with extra-hepatic manifestations.

- HEV related neurological manifestations may be due to direct effect of virus or immunological phenomenon.

- Reversible corpus callosum hyperintensity can be a rare finding of HEV related encephalopathy.

\section{Funding}

None.

Conflict of Interest

None declared.

\section{References}

1 Mushahwar IK. Hepatitis E virus: molecular virology, clinical features, diagnosis, transmission, epidemiology, and prevention. J Med Virol 2008;80(4):646-658

2 Pischke S, Hartl J, Pas SD, Lohse AW, Jacobs BC, Van der Eijk AA. Hepatitis E virus: infection beyond the liver? J Hepatol 2017;66(5):1082-1095

3 Kamar N, Bendall RP, Peron JM, et al. Hepatitis E virus and neurologic disorders. Emerg Infect Dis 2011;17(2):173-179

4 Pasha SA, Pasha SA, Suhasini T, Rao DA, Hepatitis E. Hepatitis E virus-associated acute encephalitic parkinsonism. J Assoc Physicians India 2018;66(3):92-93

5 KunLN, YianSY, Haur LS, Tjia H. Bilateral substantia nigrachanges on MRI in a patient with encephalitis lethargica. Neurology 1999;53(8):1860-1862

6 Chen XD, Zhou YT, Zhou JJ, Wang YW, Tong DM. Guillain-Barré syndrome and encephalitis/encephalopathy of a rare case of Northern China acute severe hepatitis E infection. Neurol Sci 2014;35(9):1461-1463

7 Bazerbachi F, Haffar S, Garg SK, Lake JR. Extra-hepatic manifestations associated with hepatitis E virus infection: a comprehensive review of the literature. Gastroenterol Rep (Oxf) 2016;4(1):1-15

8 Singh P, Gogoi D, Vyas S, Khandelwal N. Transient splenial lesion: further experience with two cases. Indian J Radiol Imaging 2010;20(4):254-257 
9 Tada H, TakanashiJ, Barkovich AJ, et al. Clinically mild encephalitis/ encephalopathy with a reversible splenial lesion. Neurology 2004;63(10):1854-1858

10 Belbézier A, Lagrange E, Bouillet L. [Neurologic disorders and hepatitis E: review of literature]. Rev Med Interne 2018; 39(11):842-848

11 Kobata R, Tsukahara H, Nakai A, et al. Transient MR signal changes in the splenium of the corpus callosum in rotavirus encephalopathy: value of diffusion-weighted imaging. J Comput Assist Tomogr 2002;26(5):825-828

12 Ko SY, Kim BK, Kim DW, et al. Reversible splenial lesion on the corpus callosum in nonfulminant hepatitis A presenting as encephalopathy. Clin Mol Hepatol 2014;20(4):398-401
13 Bulakbasi N, Kocaoglu M, Tayfun C, Ucoz T. Transient splenial lesion of the corpus callosum in clinically mild influenza-associated encephalitis/encephalopathy. AJNR Am J Neuroradiol 2006;27(9):1983-1986

14 Starkey J, Kobayashi N, Numaguchi Y, Moritani T. Cytotoxic lesions of the corpus callosum that show restricted diffusion: mechanisms, causes, and manifestations. Radiographics 2017;37(2):562-576

15 Fourquet E, Mansuy JM, Bureau C, et al. Severe thrombocytopenia associated with acute autochthonous hepatitis E. J Clin Virol 2010;48(1):73-74 